\title{
Article \\ Underwater Excavation Records Using Underwater Acoustic Survey: A Case Study in South Korea
}

\author{
Young-Hyun Lee ${ }^{1}$, Jin-Hoo Kim ${ }^{2}$, Sang-Hee Lee ${ }^{2}\left(\mathbb{D}\right.$ and Sung-Bo Kim ${ }^{3, *}$ (D) \\ 1 Underwater Excavation Division, Korea National Research Institute of Maritime Cultural Heritage, \\ Mokpo Jeonnam 58699, Korea; lyh2343@korea.kr \\ 2 Department of Energy and Mineral Resources Engineering, Dong-A University, Busan 49315, Korea; \\ jkim@dau.ac.kr (J.-H.K.); lsh3314@donga.ac.kr (S.-H.L.) \\ 3 Department of Drone \& Transportation Engineering, Young-San University, Gyeongnam 50510, Korea \\ * Correspondence: tamsabo@ysu.ac.kr; Tel.: +82-55-380-9504
}

check for updates

Citation: Lee, Y.-H.; Kim, J.-H.; Lee, S.-H.; Kim, S.-B. Underwater Excavation Records Using Underwater Acoustic Survey: A Case Study in South Korea. Appl. Sci. 2021, 11, 4252. https://doi.org/10.3390/ app11094252

Academic Editor: Sergio Montelpare

Received: 9 April 2021

Accepted: 4 May 2021

Published: 7 May 2021

Publisher's Note: MDPI stays neutral with regard to jurisdictional claims in published maps and institutional affiliations.

Copyright: (c) 2021 by the authors. Licensee MDPI, Basel, Switzerland. This article is an open access article distributed under the terms and conditions of the Creative Commons Attribution (CC BY) license (https:// creativecommons.org/licenses/by/ $4.0 /)$.

\begin{abstract}
The most effective method for surveying underwater archeological sites is visually identifying areas with relics or remains through diving surveys. However, during underwater excavations, it is difficult to obtain images in turbid water. Furthermore, on-site diving is costly and time-consuming. Marine acoustic geophysical survey equipment is not significantly affected by underwater turbidity, and underwater excavations often rely on geophysical equipment for surface inspections. This study aimed to improve existing underwater excavation imaging through the application of acoustic survey methods. Underwater surveys were conducted via acoustic marine geophysical survey devices at three historically significant underwater sites in South Korea: Dangampo, Nakwoldo Island, and the Battle of Myeongnyang. At the Dangampo site, surveys were conducted using three different sonar devices—side scan sonar, multibeam echo sounder, and scanning sonar-and the results were compared; scanning sonar was the most effective. The methodology was further refined during excavations at the Nakwoldo and Myeongnyang sites. Results show that the scanning sonar can produce images that are more accurate than on-site drawings produced during underwater excavations, even in turbid underwater environments. Moreover, applied in conjunction with high-frequency geophysical exploration techniques, scanning sonar can significantly increase the reliability of investigations of buried underwater remains and relics.
\end{abstract}

Keywords: marine geophysical survey; sonar; multibeam echo sounder

\section{Introduction}

In underwater archeological site surveys, marine geophysical survey (MGS) devices are used to detect underwater relics such as ancient shipwrecks. The first underwater archeological geophysical survey in South Korea was the Chilcheollyang seafloor survey conducted by the Cultural Heritage Administration in 1973 [1]. Pursuant to the Regulations on Methods and Procedures for Surface Surveying, 485 surveys of underwater archeological sites were conducted from 2005 to 2019. Nevertheless, in South Korea, no ancient shipwrecks have been detected using MGS equipment [2-5]. However, geophysical methods have been used successfully at underwater archeological site surveys, such as the successful survey of the Greek submerged vessel "Fiskardo" [6]. Furthermore, Kim [7] conducted an on-site study on the applicability of MATLAB-based Chirp Sub-Bottom Profiler data on buried cultural assets. Tamura et al. [8] investigated the stratigraphic sequence of sedimentary layers of the Amazon River, and their methodology can be applied to the surveying of potential buried cultural properties and the investigation of ancient strata as a subfield of historical geology. Kim et al. [9] investigated the physical properties of submarine sediments, which were collected by grab samplers and vibro-corers, to explore the effects of the submarine environment on the development of maritime archaeological survey techniques. Geophysical methods were used to investigate the site where a 
ship sank in 1797 in Bantry Bay, Ireland [10-13]. The purpose of the investigation was to accurately relocate the wreck, determine the extent of the site, map the seabed and underground surface rocks around the wreck, and provide a base map for a more detailed diver investigation. Simyrdanis et al. [14] and Weiss et al. [15] also applied geophysical methods to underwater archaeology. In addition, Dhoop et al. [16] and Ono et al. [17] used sonar equipment to measure the 3D geometric shapes of sunken ships and underwater iron artifacts. Hu et al. [18] conducted a resolution analysis using a variety of sonar systems, including a side scan sonar (SiSS) and underwater acoustic exploration equipment on the same target. McCarthy et al. [19] described the application of sonar, laser, optics, and other sensor-based technologies that capture ground, intertidal, subsea, and sub-segment deposits in 3D and high resolution, while Sakellariou et al., Kim et al. [20] generated 2D data as 3D data using a commercial 2D Chirp SBP system with a newly designed recording system(Daejeon, Korea) at the site where an ancient wooden shipwreck was buried, and the ancient shipwreck was successfully imaged through 3D rendering. Sakellariou et al. [21] conducted comparative studies on traditional underwater survey methods in the Aegean Sea by comparing the results to those derived through the application of the latest techniques in geophysical exploration.

These studies highlight the importance of promoting technological advancements in geophysical survey methods and investigating their applicability to excavation surveys of buried cultural relics.

This study aimed to upgrade the current survey imaging methodology by applying MGS techniques to underwater excavation (UE) and enhancing the utility of MGS devices in the field of underwater archaeology. To achieve these objectives, we compared the performances of three different MGS systems using data collected in the waters off Dangampo, Taean County (hereinafter the "Dangampo site") in 2017. Furthermore, we determined the method best suited for scanning sonar (SS) image mapping based on geophysical surveys at two UE sites, one in the waters off Nakwol Island, Yeonggwang County (hereinafter "Nakwoldo site"), and the other at site of the Battle of Myeongnyang near Jindo (hereinafter "Myeongnyang site"). These surveys were conducted in 2018 and 2019, respectively. In this paper, we outlined the on-site survey findings and present the methods for imaging seafloor surfaces using MGS equipment.

Herein, we investigated the application of marine geophysical exploration equipment using sound waves through underwater excavation surveys at excavation sites in South Korea. To this end, the marine physics exploration equipment was operated and tested at the underwater excavation sites of Dangampo Sea in Taean, Chungcheongnam-do, Nakwoldo Sea in Yeonggwang, Jeollanam-do, and Myeongnyangdae-ro, Jindo, Jeollanam-do.

\section{Background Information}

Underwater visibility is limited even in clear water, which makes it difficult to obtain a photograph in which relics and remains are easily identifiable, as can be done with aerial images for land excavations. Therefore, the most effective way to illustrate the overall shape of surveyed objects is on-site drawings. However, the available diving time for on-site investigations and measurements is limited, and relics on the seafloor may be swept away by tidal currents. Moreover, underwater on-site measurements and photogrammetry cannot be performed below a certain level of underwater visibility, and the accurate recording of remains is challenging if relics are dispersed over a large seafloor area. For example, the Myeongnyang site is characterized by a turbid underwater environment and strong tides, significantly affecting photographing and surveying the site. Consequently, the current survey report comprises a map indicating previously surveyed sections only and does not provide enough information to infer the state of the remains, such as the topographic profile of the seafloor or the presence of foreign objects.

Similar to land archeology, where burial depths and structures of relics can be investigated by geophysical surveys that eliminate the need for excavations for research and exploration, underwater archeology can utilize MGS devices for investigations. However, 
the geophysical surveying of underwater environments requires different devices to those used for land surveys. For example, Carreón-Freyre et al. [22] utilized ground-penetrating radar in a land archeological investigation using electromagnetic waves to probe below the surface. However, electromagnetic waves are not suitable for underwater investigations because they are strongly dampened in water. In contrast, sound waves travel faster and farther in water than they do in air. This characteristic has led to the development of acoustic MGS devices, such as the SiSS and the echo sounder, which can detect objects on the seafloor, and sub-bottom profilers, which are used to map the strata beneath the seafloor. As geophysical survey devices use sound waves that are not affected by underwater turbidity, they yield relatively high-quality images under conditions that limit visual or optical photography [23].

\section{Dangampo Site: Equipment Testing}

\subsection{Experimental Setup}

Generally, sediment removal is involved in UEs, which can alter the seafloor profile. Therefore, the application of acoustic MGS systems to UEs of cultural properties is expected to provide useful images of excavation sites in turbid underwater environments, similar to the use of aerial photography for documenting land excavations. During the UE at the Dangampo site in 2017, three different types of MGS devices using sound waves were employed for identifying the device best suited for imaging the UE sites.

The underwater relics at the Dangampo site are distributed on the seafloor in Cheonsuman Bay, between the Taean and Anmyeondo Islands, where the Anmyeon Canal starts. The site covers an area of $500 \mathrm{~m}$ (latitudinal) $\times 200 \mathrm{~m}$ (longitudinal) and has been provisionally designated as a historical site. Two UE missions were carried out at this site during the periods of October 10-31, 2017, and April 4-22, 2018.

During the first excavation mission in 2017, a sediment removal survey was conducted in the area where many relics had been found in a time-constrained exploration in 2016. The site-surface was characterized by a thick layer of stones larger than fist-size, with a sandy silt soil layer underneath. Relics were buried between the stones or within the soil layer, and underwater visibility was fairly good. For the sediment removal survey, an area of $20 \mathrm{~m} \times 20 \mathrm{~m}$ along the latitudinal and longitudinal axes was selected. This area was then quartered into four $10 \mathrm{~m} \times 10 \mathrm{~m}$ squares, and each square was quartered again, resulting in a 16-square grid of $5 \mathrm{~m} \times 5 \mathrm{~m}$. Sediment removal lines were set at $1 \mathrm{~m}$ spacings along the latitudinal axis, and the sediment removal depth was set to $20-30 \mathrm{~cm}$. The stones and soil removed from a sediment removal line were moved to the previously emptied line, thereby leaving the entire sediment removal area (SRA) with a ridge-furrow surface profile after sediment removal completion.

During the Dangampo site UE, an SiSS, multibeam echo sounder (MBES), and SS were used to record the seafloor of the survey area and the SRA. Since these survey systems mapped the seafloor using sound waves, we expected the obtained recordings of the seafloor to be changed by the excavation.

\subsubsection{Side Scan Sonar}

The SiSS is a survey system most widely used in the field of marine research. A towfish, which scans the seafloor, is submerged and towed behind a boat or ship. The transducers installed on both sides of the towfish emit sound waves and receive the acoustic return from the seafloor. The recording device connected to the towfish measures the sound pressure of the returning sound waves and expresses the track of the towfish as a single line. The transducers continuously emit sound waves while being towed over the seafloor, resulting in continuous lines that connect to form a plane image. 
An SiSS survey was conducted at the Dangampo site before the sediment removal survey on the morning of October 26 using a DSME Utech S-150 SiSS, with a frequency range of 400-1250 kHz. Owing to its small footprint and simple structure, the equipment could be taken aboard a rubber boat to sweep the site $(500 \mathrm{~m}$ (latitudinal) $\times 200 \mathrm{~m}$ (longitudinal)), and a frequency of $400 \mathrm{kHz}$ was used. Using a $105 \mathrm{~m}$ swath, i.e., a strip of seafloor covered by one sweep, it was possible to attain more than $100 \%$ overlap between adjacent swaths by conducting three round trips along the latitudinal axis. Additionally, it was possible to identify the SRA at the site. To obtain high-quality results, we repeated the survey several times using the following two combinations of frequency and swath: $400 \mathrm{kHz}$ and $105 \mathrm{~m}$, and $1250 \mathrm{kHz}$ and $75 \mathrm{~m}$.

\subsubsection{Echo Sounder}

An echo sounder records water depth by measuring the time required for a sound wave to travel from a transducer to the seafloor and back. An MBES emits multiple beams and collects a large range of information, which can be used as data for the 3D mapping of the seafloor topography (Figure 1).

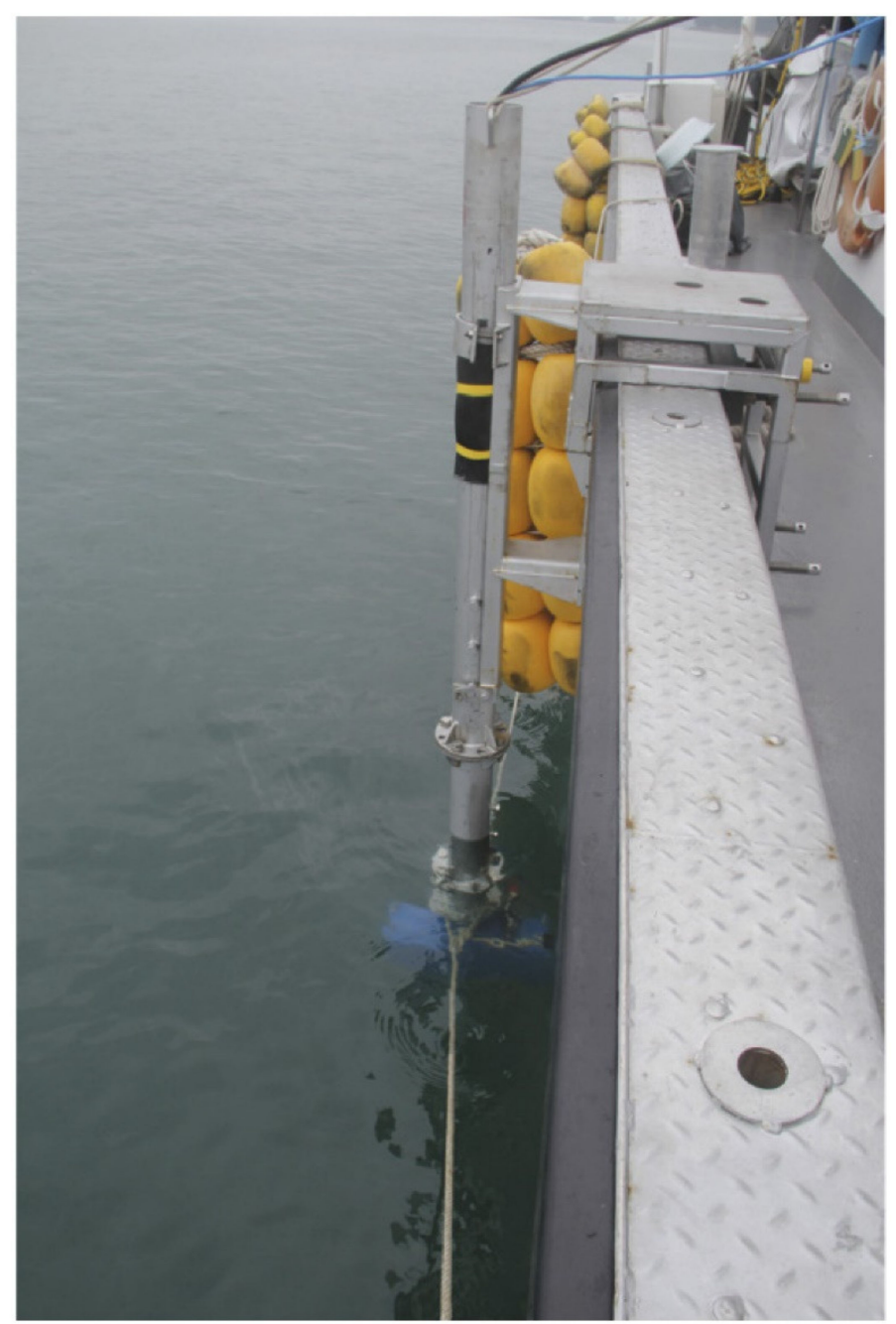

Figure 1. Photograph of a multibeam echo sounder transducer. 
The MBES survey at the Dangampo site was conducted on October 27, before the scheduled sediment removal survey, using an R2Sonic 2024 Wideband Multibeam Echosounder. The multibeam transducer of this model emits 256 beams at $400 \mathrm{kHz}$ in one sweep. We installed the MBES on the ship Sea Muse (18 ton) as it was too cumbersome for a small boat, and we conducted the survey during the high tide. In the northern part of the site, the water was too shallow for the survey vessel to approach. Hence, only half of the site (500 m (latitudinal) $\times 100 \mathrm{~m}$ (longitudinal)) was surveyed. The swath of the MBES varied depending on the water depth; typically, the swath was approximately four times the water depth. Given that the water depth at the Dangampo site ranged from 4 to $10 \mathrm{~m}$, the swath of the echo sounder ranged between 16 and $40 \mathrm{~m}$. Accordingly, the survey line, spacing was set to $10 \mathrm{~m}$ along the longitudinal axis, and the seafloor was surveyed while the ship navigated back and forth 7.5 times along the latitudinal axis.

\subsubsection{Scanning Sonar}

An SS is an underwater sounding apparatus that measures pressure by transmitting a sound wave from a transducer and receiving echoes reflected from underwater targets, similar to the SiSS. However, the SS operates from a fixed position on the seafloor, where it performs 360-degree sonar sweeps and produces complete circular images.

When operating an SS system, a transducer is usually placed on the seafloor mounted to a tripod. The tripod is designed to keep the transducer perpendicular to the seafloor even if it is tilted. In addition, a weight is attached to its bottom to resist tidal currents.

The SS used at the Dangampo site was a Kongsberg Mesotech 1171 series sonar. Its operating frequency and range were $600-1200 \mathrm{kHz}$ and $0.5-100 \mathrm{~m}$, respectively. At the site, we selected a survey area of $260 \mathrm{~m}$ (latitudinal) $\times 180 \mathrm{~m}$ (longitudinal) because measuring the entire site would be a very time-consuming process due to the necessity of moving and reinstalling the SS several times to obtain high-quality data for each section. While lengthening the range to survey a larger area in one sweep is possible, this approach significantly reduces the resolution as a longer range degrades the reflection coefficient.

An SS survey of the site was conducted during the highest tide on October 14 and 15 to ensure the best data quality by minimizing the effect of tidal currents on the transducer. Prior to the survey, we checked the coordinates of the 24 positions to install the SS and acquired data by descending the tripod on which the transducer was mounted from the rubber boat to the seafloor. The frequency and range were set to $675 \mathrm{kHz}$ and 30 or $50 \mathrm{~m}$. After operating the SS for two days, data were obtained from only eight of the originally planned 24 target positions due to the unexpectedly long SS installation time and short duration of the high tide period necessary for surveying. The SS survey of the SRA was conducted on October 27. We obtained data with the transducer placed next to the SRA, with the frequency and range set to $675 \mathrm{kHz}$ and $25 \mathrm{~m}$, respectively.

\subsection{Results and Discussion \\ 3.2.1. Side Scan Sonar}

The SRA images acquired by the SiSS displayed a dense distribution of shades distinct from the other images. Comparing the images acquired at 400 and $1250 \mathrm{kHz}$, at $400 \mathrm{kHz}$, only the SRA could be distinguished from the remaining seafloor in the images acquired, whereas the images obtained at $1250 \mathrm{kHz}$ delivered an accurate image of the seafloor topography of the SRA. Despite a shortening of the propagation distance, higher frequencies obtain higher resolution images. However, the SRA shape in the images was distorted due to the unsteady speed, depth, and direction of the towfish. Despite repeated surveying around the SRA in an effort to acquire high-quality images, obtaining an accurate picture of the SRA remained difficult (Figure 2). 


\begin{tabular}{|c|c|c|c|}
\hline $\begin{array}{c}\text { N3W2 } \\
(15 \text { area })\end{array}$ & $\begin{array}{c}\text { N3W1 } \\
(14 \text { area })\end{array}$ & $\begin{array}{c}\text { N3E1 } \\
(11 \text { area })\end{array}$ & $\begin{array}{c}\text { N3E2 } \\
(12 \text { area })\end{array}$ \\
\hline $\begin{array}{c}\text { N2W2 } \\
(16 \text { area })\end{array}$ & $\begin{array}{c}\text { N2W1 } \\
(13 \text { area })\end{array}$ & $\begin{array}{c}\text { N2E1 } \\
(9 \text { area })\end{array}$ & $\begin{array}{c}\text { N2E2 } \\
(10 \text { area })\end{array}$ \\
\hline $\begin{array}{c}\text { N1W2 } \\
(2 \text { area })\end{array}$ & $\begin{array}{c}\text { N1W1 } \\
(1 \text { area })\end{array}$ & $\begin{array}{c}\text { N1E1 } \\
(8 \text { area })\end{array}$ & $\begin{array}{c}\text { N1E2 } \\
(7 \text { area })\end{array}$ \\
\hline $\begin{array}{c}\text { S1W2 } \\
(3 \text { area })\end{array}$ & $\begin{array}{c}\text { S1W1 } \\
(4 \text { area })\end{array}$ & $\begin{array}{c}\text { S1E1 } \\
(5 \text { area })\end{array}$ & $\begin{array}{c}\text { S1E2 } \\
(6 \text { area })\end{array}$ \\
\hline
\end{tabular}

Sediment removal area during the side scan sonar survey

\begin{tabular}{|c|c|c|c|}
\hline $\begin{array}{c}\text { N3W2 } \\
(15 \text { area })\end{array}$ & $\begin{array}{c}\text { N3W1 } \\
(14 \text { area })\end{array}$ & $\begin{array}{c}\text { N3E1 } \\
(11 \text { area })\end{array}$ & $\begin{array}{c}\text { N3E2 } \\
(12 \text { area })\end{array}$ \\
\hline $\begin{array}{c}\text { N2W2 } \\
(16 \text { area })\end{array}$ & $\begin{array}{c}\text { N2W1 } \\
(13 \text { area })\end{array}$ & $\begin{array}{c}\text { N2E1 } \\
(9 \text { area })\end{array}$ & $\begin{array}{c}\text { N2E2 } \\
(10 \text { area })\end{array}$ \\
\hline $\begin{array}{c}\text { N1W2 } \\
(2 \text { area })\end{array}$ & $\begin{array}{c}\text { N1W1 } \\
(1 \text { area })\end{array}$ & $\begin{array}{c}\text { N1E1 } \\
(8 \text { area })\end{array}$ & $\begin{array}{c}\text { N1E2 } \\
(7 \text { area })\end{array}$ \\
\hline $\begin{array}{c}\text { S1W2 } \\
(3 \text { area })\end{array}$ & $\begin{array}{c}\text { S1W1 } \\
(4 \text { area })\end{array}$ & $\begin{array}{c}\text { S1E1 } \\
(5 \text { area })\end{array}$ & $\begin{array}{c}\text { S1E2 } \\
(6 \text { area })\end{array}$ \\
\hline
\end{tabular}

Sediment removal area during the multibeam echo sounder survey

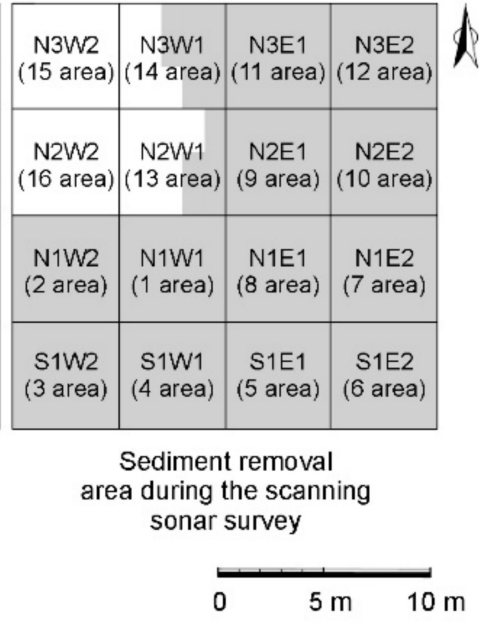

Figure 2. Map codes indicating the geophysical survey sediment removal section at the Dangampo site removal section after the operation).

\subsubsection{Echo Sounder}

The SRA images acquired by the MBES showed corrugated profiles compared with the surrounding seafloor. Unlike the images acquired by the SiSS, no distortion of the overall shape was visible due to the post-correction of the elements that may have caused distortion, as detailed in Section 3.2.4. However, the topographical features within the SRA were not expressed as clearly as expected, and the results had a similar resolution to the $400 \mathrm{kHz}$ SiSS images.

\subsubsection{Scanning Sonar}

The images acquired by the SS did not show any significant errors or distortions, even without post-correction, and accurately displayed the topographic features of the SRA. This accuracy was attributed to the data acquisition method because the fixed position of the transducer on the seafloor prevents its exposure to various factors that would adversely affect the image quality, with the exception of tidal currents. Although the $5 \mathrm{~m} \times 5 \mathrm{~m}$ squares were not very evident, the initial grid of $10 \mathrm{~m} \times 10 \mathrm{~m}$ squares was clearly distinguishable. Moreover, the ridge-furrow surface profile caused by the sediment removal survey could be confirmed on the survey line along which the sediment removal survey had been conducted. The only disadvantage of the SS observations in this study was the diminishing resolution with increasing distance from the transducer.

\subsubsection{Performance Evaluation}

The wide swath of the SiSS proved advantageous for the geophysical survey as it enabled the rapid surveying and real-time monitoring of the scanned objects, which was useful for detecting anomalous objects (Figure 3). However, the images acquired showed distorted aspect ratios because of the irregular towing speeds, which were reflected in the vertical axis of the acquired images. As a result, the SiSS was not effective in mapping the overall seafloor topography.

In contrast, the MBES plotted the results as 3D maps displaying the underwater topography (Figure 4). The eastern part of the site had a water depth of 9-10 $\mathrm{m}$, which decreased from around the midpoint onwards to a final depth of 4-5 $\mathrm{m}$ in the southern part. Accurate topographic features were distinguishable due to the post-correction of the raw data based on information about the side- and lengthwise shaking of the vessel, navigation speed, depth-dependent speed of a sound wave, and tidal change during surveying. However, this process was time-consuming, and great care was taken to avoid the accidental removal of important information during data cleaning. These inconveniences lowered the efficacy of the MBES for detecting anomalous objects compared with the SiSS system. 


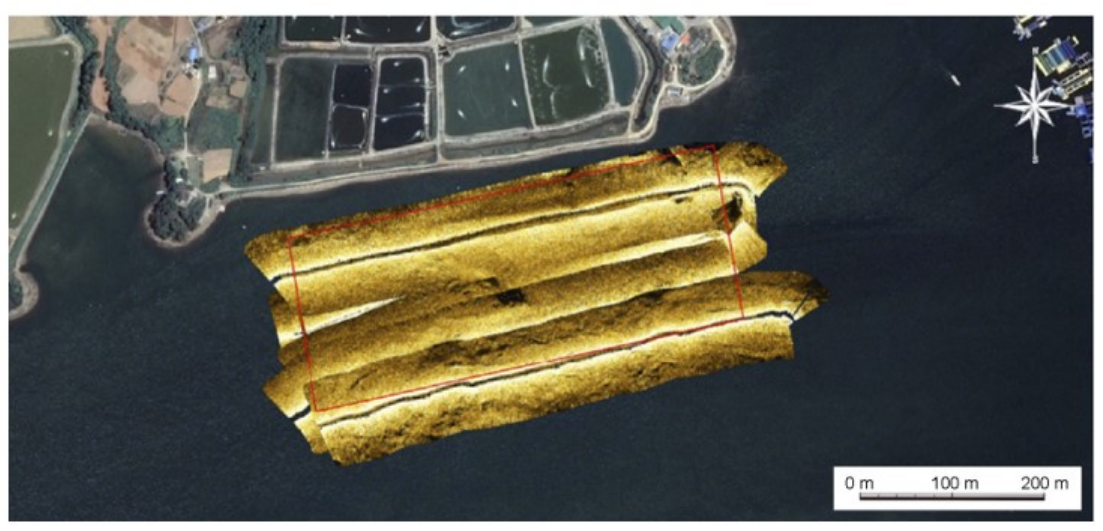

Figure 3. Surveying range of the side scan sonar system at the site ( $\square$ : the site, Google Earth).

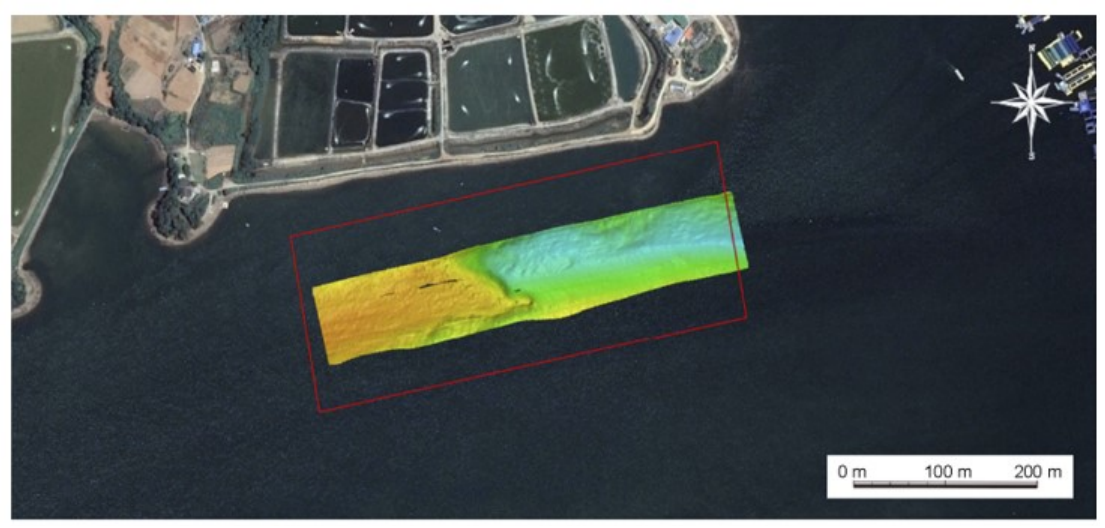

Figure 4. Surveying range of the multibeam echo sounder at the site ( $\square$ : the site, Google Earth).

The main disadvantage of the SS method is the length of time required to survey a large area, which requires moving between scan positions by repeatedly placing the transducer on different areas of the seafloor. For this reason, the surveying could not be completed as scheduled, although only a partial area of the site was selected for the survey.

Overall, the SiSS was effective for rapidly obtaining information about the seafloor over a large area, but it was difficult to obtain accurate images. The MBES exhibited disadvantages in terms of its limited survey conditions and the considerable time required to process the data and obtain results. However, it effectively mapped the overall topography of the area. The SS was not efficient for surveying a large area because of the time required to set up the equipment.

Our results indicated that the SiSS obtained high-resolution images when operated at a $1250 \mathrm{kHz}$ frequency. However, repeated surveying was necessary to obtain high-quality images, and it was difficult to correct distortions incurred during the survey. Despite the advantage of no or little distortion owing to post-correction, the MBES did not efficiently record the SRA because of its low resolution. Conversely, the SS was straightforward to operate and yielded excellent images, even without post-correction.

Therefore, through the comparative testing of the three survey devices conducted at the first UE at the Dangampo site, the SS was identified as the best-suited instrument for recording the sediment removal survey site. 


\subsubsection{Second Excavation: Result Verification and Method Refinement}

Accordingly, the SS was selected for use during the second UE conducted in 2018 to record the SRA at the Dangampo site. During the second excavation with an SRA of $20 \mathrm{~m}$ $\times 20 \mathrm{~m}$, the remaining sediment from the first excavation was surveyed. A $10 \mathrm{~m} \times 10 \mathrm{~m}$ square area to the east of the sediment area removed in the first excavation was selected and subdivided into a grid of four $5 \mathrm{~m} \times 5 \mathrm{~m}$ squares to continue the sediment removal operation (Figure 5).

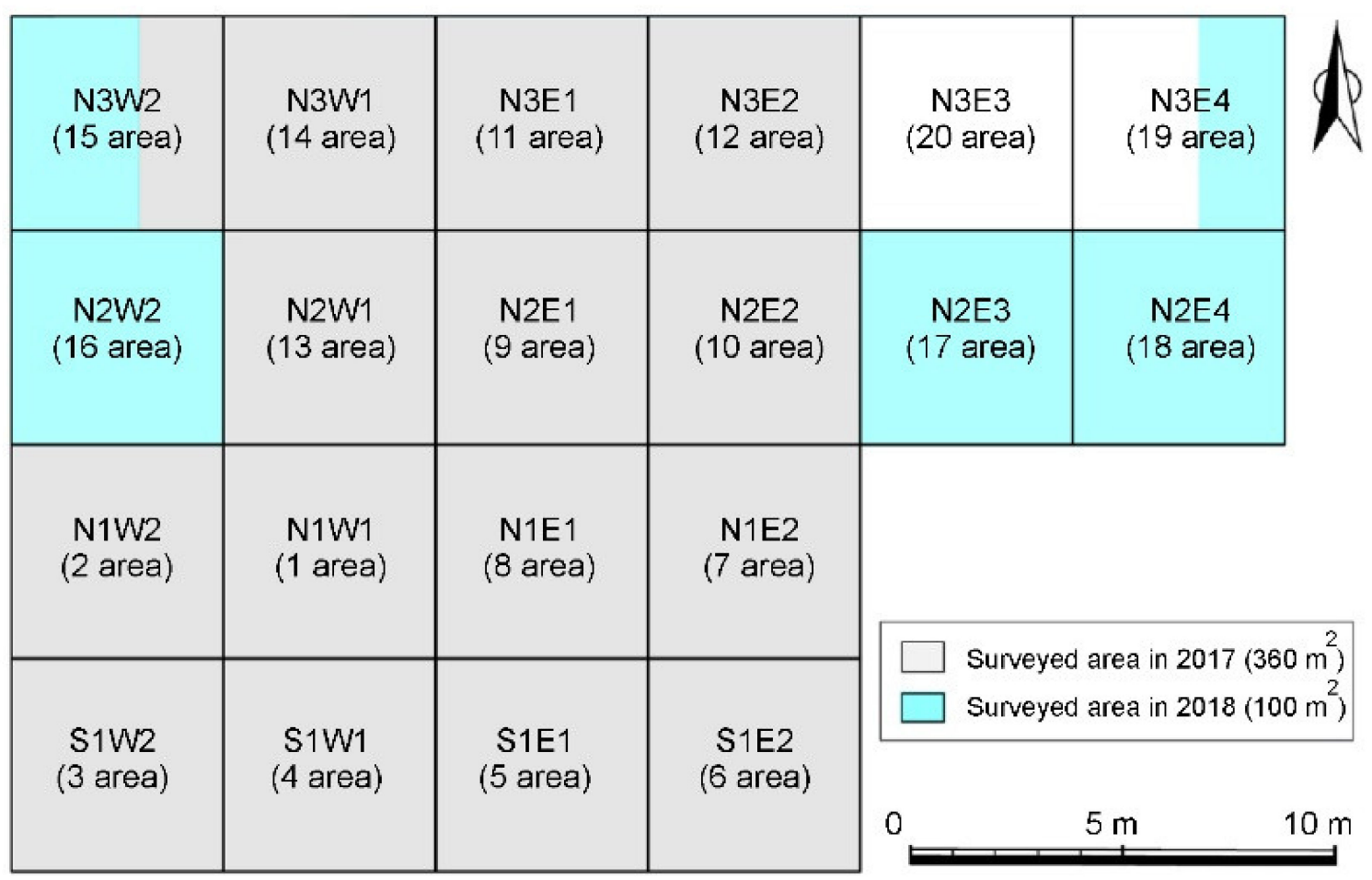

Figure 5. Sediment removal area of the second underwater excavation at the Dangampo site.

To record the SRA, the SS transducer was positioned next to it and operated at a frequency of $675 \mathrm{kHz}$, with a swath varying between 25 and $40 \mathrm{~m}$. The $25 \mathrm{~m}$ swath was not sufficient to capture the entire SRA, which was larger during the second excavation than the first removal operation. Using a $40 \mathrm{~m}$ swath, the entire SRA was captured. However, the resolution decreased with increasing distance from the center. To address this problem, SS images were collected at three points around the SRA using the $25 \mathrm{~m}$ swath. The three images were combined into one mosaic image of the entire area. The mosaic image of the three $25 \mathrm{~m}$ swath images captured at three different positions had a higher resolution than the image taken by the $40 \mathrm{~m}$ swath at one point (Figure 6). 


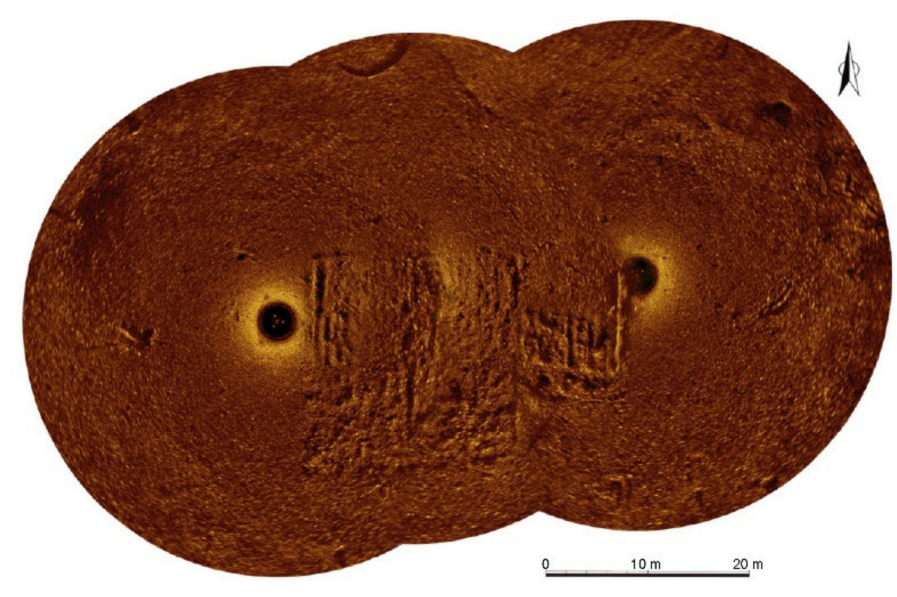

Figure 6. Mosaic scanning sonar image (frequency: $675 \mathrm{kHz}$; swath: $25 \mathrm{~m}$ ) of the sediment removal area of the second underwater excavation at the Dangampo site.

\section{Application Case: Poor Underwater Visibility (Nakwoldo Site)}

The experiments conducted at the Dangampo site identified the SS as the acoustic device best suited for recording the seafloor topography. However, given that the Dangampo site is characterized by fairly good underwater visibility, it was necessary to test the performance of the SS in a turbid environment with poor underwater visibility. Therefore, we performed SS imaging during UEs at the Nakwoldo and Myeongnyang sites in 2018 and 2019.

After the discovery and identification of numerous relics, including the Goryeo celadon, in the waters east of Nakwoldo (Yeonggwang County), a UE was conducted from May 4 to November 5, 2018. During the Nakwoldo excavation, the aim was to survey a large seafloor area to determine the relic distribution pattern and discover where relics are concentrated, or the remains of a shipwreck may be found.

\subsection{Experimental Setup}

At the Nakwoldo site, the visibility generally did not exceed $10 \mathrm{~m}$, and the researcher diving to the seafloor had difficulties identifying his position and marking the positions of the relics found. This issue was addressed by marking each meter with insulation tape along the rope and installing a $20 \mathrm{~m} \times 20 \mathrm{~m}$ grid of survey lines at $1 \mathrm{~m}$ intervals along the latitudinal axis. Thus, the researcher could identify his position by moving along the grid with the survey rope in his hand. A probe rod was used to probe the subsurface of the seafloor. In this way, five sections (A-E) were surveyed at the Nakwoldo site, of which section A occupied the largest area (120 m (latitudinal) $\times 220 \mathrm{~m}$ (longitudinal)). A small number of shells was mixed with solid silt soil at the site, and the average depth was approximately $10 \mathrm{~m}$. Expanding the survey area southward, the researcher surveyed two $10 \mathrm{~m} \times 10 \mathrm{~m}$ grids and fifty-nine $20 \mathrm{~m} \times 20 \mathrm{~m}$ grids.

In the experiment conducted at the Dangampo site in 2017, the SS had difficulty surveying a large site area due to time constraints. In the second UE of the Dangampo site in 2018, we were able to produce a mosaic image of the entire survey area by combining three SS images, indicating that, time permitting, an image of a large area can be produced using an SS system. During section A, the diving survey at the Nakwoldo site, the SS was submerged to the seafloor from the boat (the Nurian) at each new position, where it recorded the seafloor morphology and the survey progress. The frequency and swath used were $675 \mathrm{kHz}$ and $50 \mathrm{~m}$. Eleven images acquired from individual points were combined into a mosaic image of the entire surveyed seafloor surface of section A (Figure 7). Lastly, we produced an excavation chart by drawing a grid over the mosaic image. 


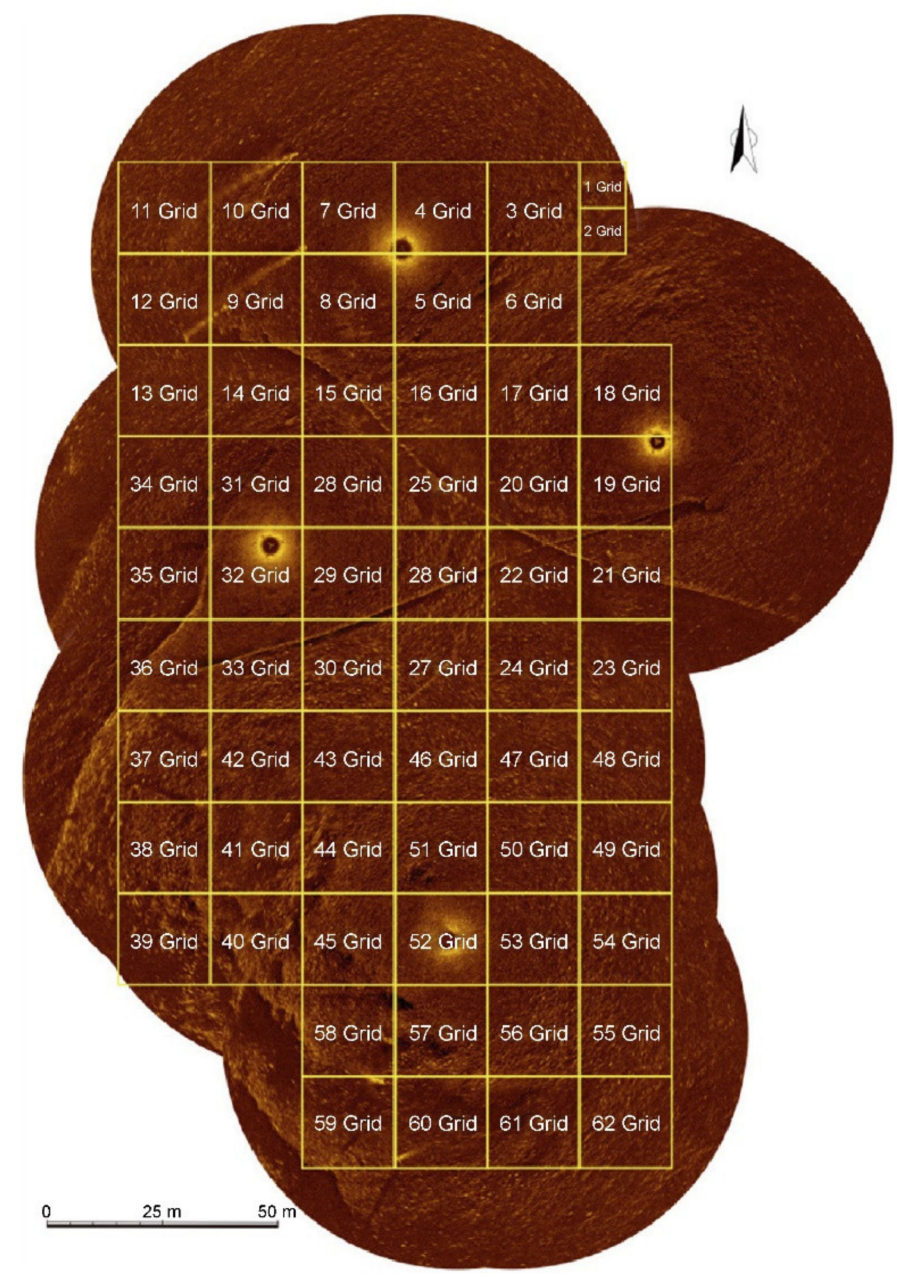

Figure 7. Scanning sonar image of section A of the Nakwoldo underwater excavation site (frequency: $675 \mathrm{kHz}$; swath: $50 \mathrm{~m}$ ).

\subsection{Results and Discussion}

As shown in Figure 7, the seafloor of section A had a predominately flat surface, with a corrugated profile visible only partially in the southern part. The most salient feature within section A was a long wire and waste nets lying flat on the seafloor in the form of a large X. The wire ran southeastward from grid A9, passing through grid A21 and the eastern boundary, and the waste nets were situated northeastward from grid A36 to grid A19. The presence of the wire and waste nets was confirmed during the diving survey. However, the location could only partially be confirmed due to poor visibility.

During the Nakwoldo site UE, we produced a chart using the method for drawing conventional underwater relic distribution maps. The locations of the excavated relics, wire, and waste nets were marked on this chart (Figure 8). A comparison of the chart drawn using the traditional method and the chart drawn onto the SS mosaic image revealed that the latter was more effective in constraining the conditions of the survey site. However, the rope installed to probe the seafloor was too thin to be identified on the SS image. Nevertheless, no significant changes occurred because no sediment removal survey was conducted. However, it hindered the process of combining the SS images due to the lack of a suitable reference point [7]. 


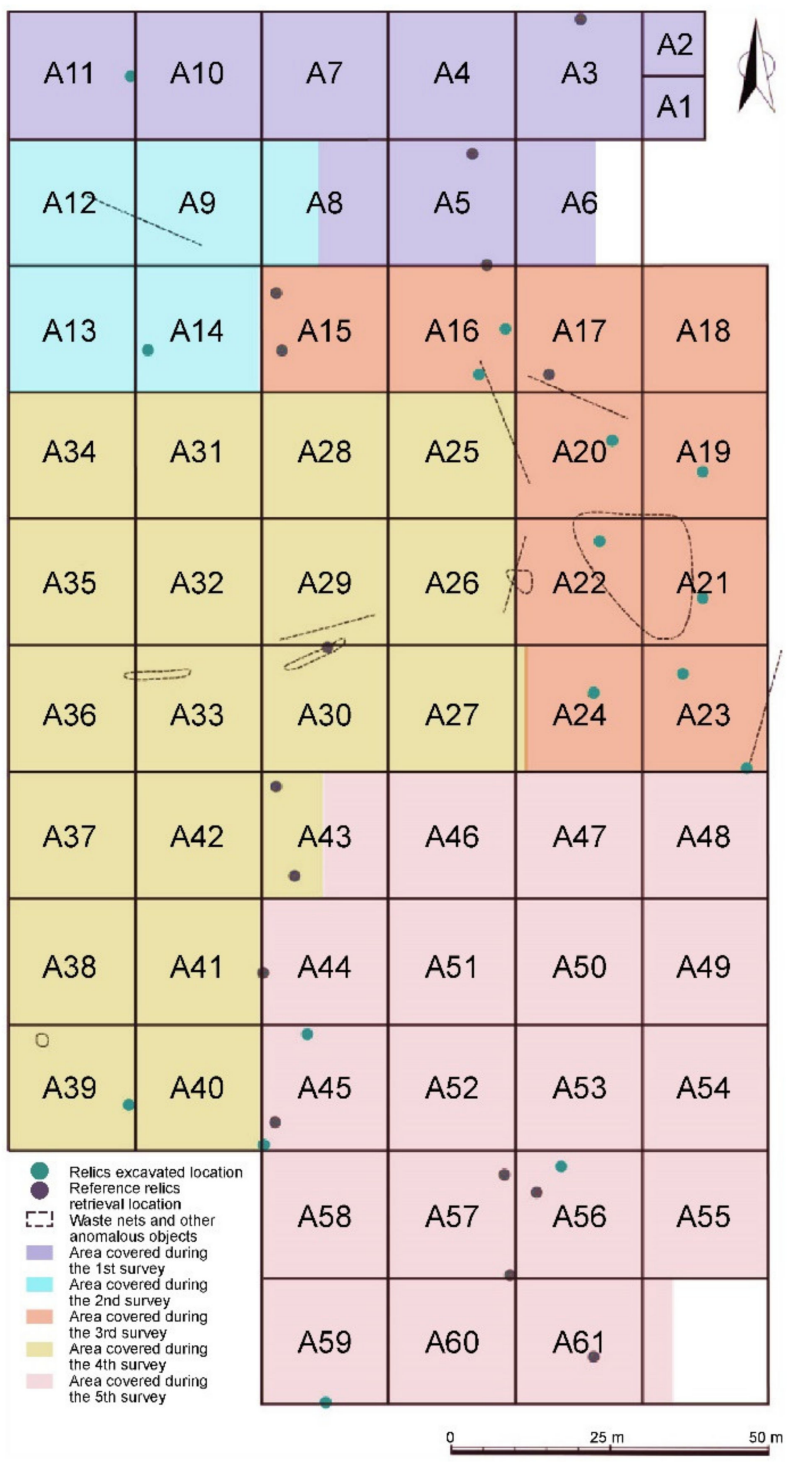

Figure 8. Survey chart of section A of the Nakwoldo underwater excavation site.

Conducting an SS survey for a large area at the Dangampo site was challenging because of the time constraints. However, at the Nakwoldo site, it was possible to obtain an image of the entire survey area by operating the SS at every vessel stop during the survey period. Conversely, the lack of a clear reference point at this site complicated the process of combining the image series into a full mosaic image.

\section{Application Case: Method Refinement (Myeongnyang Site)}

To effectively combine a series of SS images, the presence of an object that is clearly distinguishable on the seafloor surface and can be used as a reference point is crucial. However, such an object is not always available, or its position may change mid-survey. Therefore, placing an artificial object in the survey site that effectively reflects sound waves without disturbing the survey is essential. Therefore, during the Myeongnyang site UE mission in 2019, we operated the SS after installing a reflector on the seafloor to test the practical efficacy of fixing an artificial object as a reference point.

\subsection{Experimental Setup}

The Myeongnyang site is an underwater relic, where UEs have been underway since 2012. Since then, a variety of relics have been excavated and identified, including Goryeo celadon incense burners, with an openwork design and gunpowder weapons used in 
naval battles in the Joseon Dynasty. During the sixth excavation conducted from 7 July to 27 October 2019, we carried out an SS trial excavation in section C, where the gunpowder weapons were discovered during the first excavation. The trial excavation was performed within an area of $70 \mathrm{~m}$ (latitudinal) $\times 60 \mathrm{~m}$ (longitudinal). The water depth ranged from 5-13 m, and the underwater visibility was $10-20 \mathrm{~cm}$ with the lights on. The seafloor was covered in a silt soil with mixed-in shells, and the soil layer thickness and pebble and stone quantity increased westward. A $50 \mathrm{~m}$-long rope was set up along the latitudinal axis with six $1 \mathrm{~m}$ wide trenches at $10 \mathrm{~m}$ intervals. A southward longitudinal trench was constructed over a length of $60 \mathrm{~m}$, and an additional two trenches were constructed to the west of the study area in the 20-50 m section. The sediments were removed to depths of $0.1-1 \mathrm{~m}$, after which the subsurface was too hard for digging.

At the Myeongnyang site, a reflector was installed on the seafloor to achieve an accurate mosaic image of multiple sonar images. The reflector was fabricated in a hemispherical shape with a diameter of $20 \mathrm{~cm}$, shaped after a radar reflector for vessels, and mounted on the handle of a probe rod used to fix it to the seafloor (Figure 9). A reflector was installed every $10 \mathrm{~m}$ along the probing trench at a height of $50 \mathrm{~cm}$ from the seafloor. The SS was operated from a barge, and the seafloor survey was repeated at every point the barge moved to as the probing operation advanced. The frequency was set to $675 \mathrm{kHz}$, and the swath was set to $25 \mathrm{~m}$ and $40 \mathrm{~m}$ (Figure 10).

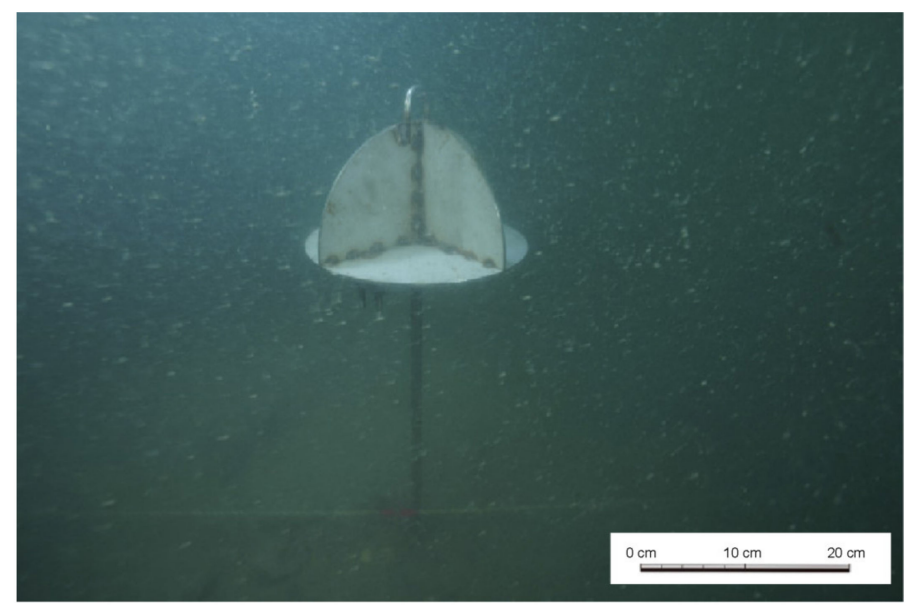

Figure 9. Reflector installed on the seafloor.

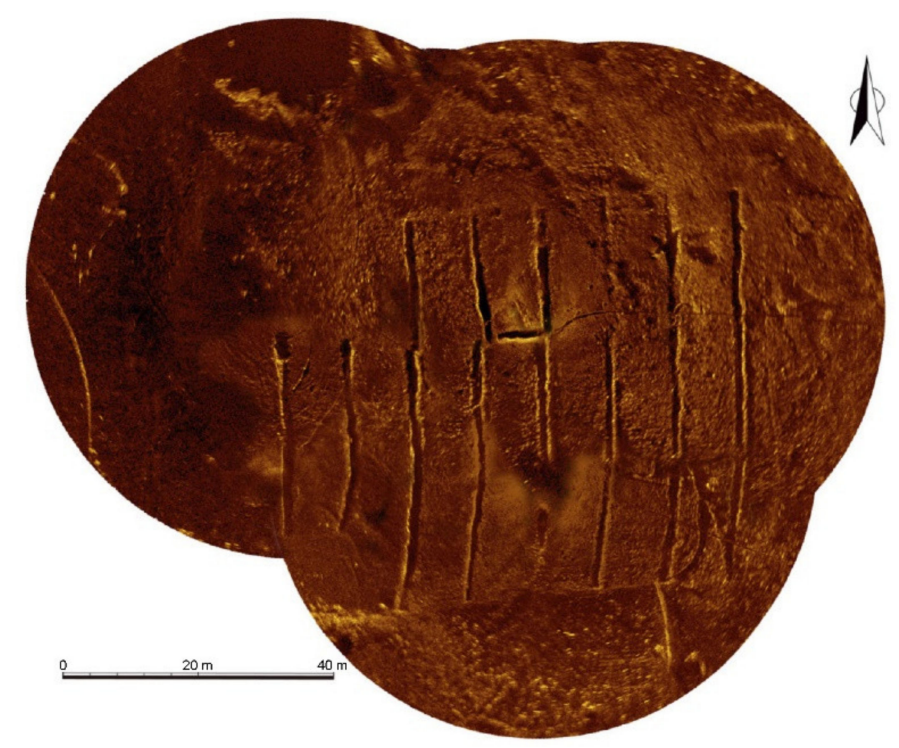

Figure 10. Scanning sonar mosaic image obtained from the trial excavation during the sixth Myeongnyang site underwater excavation (frequency: $675 \mathrm{kHz}$; swath $40 \mathrm{~m}$ ). 


\subsection{Results and Discussion}

In the sonar images obtained at the Myeongnyang site, the locations of the reflector were displayed in red in contrast to the surroundings. The data indicated that the reflector strongly reflected the sound waves. The reflector was identified in every sonar image, facilitating the production of the mosaic image, and a complete sonar image of the entire survey area was produced (Figure 10). The mosaic image shows the trench that should run southward gradually skewing westward. This discrepancy between the perception of the direction during the diving survey and the actual direction was likely due to the poor underwater visibility. Moreover, it demonstrates that SS imaging contributes to a more accurate understanding of the survey site, even in adverse underwater environments.

\section{Conclusions}

In this study, we investigated various imaging methods during UEs with acoustic MGS equipment. Specifically, three acoustic MGS devices were used in the waters off Dangampo, Taean County; Nakwoldo Island, Yeonggwang County; and at the site of the Battle of Myeongnyang near Jindo Island from 2017 to 2019 to investigate the advantages and disadvantages of different survey imaging methods. At the Dangampo site, SS proved to be more efficient than SiSS and MBES for SRA imaging. At the Nakwoldo site, a series of SS images were combined into a full image covering the entire survey area, which was then used to produce a survey chart. At the Myeongnyang site, a reflector was installed on the seafloor at regular intervals for use as a reference point to increase the accuracy of the final mosaic image. We verified that a high-quality image of the survey site could be obtained using an SS, even in turbid underwater environments where measurements or photogrammetry are difficult to perform.

The primary limitation to the generalization of our findings is that the MGS equipment testing was performed in areas where underwater relics were dispersed. Potential discoveries of ancient shipwrecks may require additional preparatory measures for rapid and accurate surveying under conditions not conducive to photogrammetry. Given that the seafloor areas where relics are dispersed are generally extensive and flat, unlike ancient shipwreck sites that are narrow and three-dimensional, the methods presented in this study cannot be used without further adjustment. It is expected that various survey methods that are able to overcome adverse conditions will be developed in future research. Furthermore, we believe that the application of the SS methodology in conjunction with high-frequency geophysical exploration techniques will increase the reliability of investigations of buried underwater remains and relics.

The proposed geophysical survey techniques for excavation research have been applied to various subjects in underwater archeological research, including ancient shipwrecks [16], underwater remains, and relics, and the results of this study confirm their applicability. Furthermore, the future application of geophysical and sonar techniques during underwater excavation research will represent an effective approach for checking the progress of the excavation and exploration of relics. This study is the first to have researched the progress of underwater excavations in South Korea using this technology, and we will continue to collect relevant scientific data that may lead to improvements in underwater excavations through continuous research.

Author Contributions: Conceptualization, S.-B.K. and Y.-H.L.; methodology, J.-H.K.; software, S.H.L.; validation, S.-B.K., Y.-H.L. and S.-H.L.; formal analysis, J.-H.K.; investigation, Y.-H.L. and S.-B.K.; resources, Y.-H.L.; data curation, J.-H.K.; writing—original draft preparation, Y.-H.L.; writingreview and editing, S.-B.K.; visualization, S.-H.L.; supervision, J.-H.K..; project administration, S.-B.K.; funding acquisition, Y.-H.L. All authors have read and agreed to the published version of the manuscript.

Funding: This research was funded by the academic research grants from Young-San University and the Korea National Research Institute of Maritime Cultural Heritage.

Institutional Review Board Statement: Not applicable. 
Informed Consent Statement: Not applicable.

Data Availability Statement: Data sharing is not applicable to this article.

Acknowledgments: Not applicable.

Conflicts of Interest: The authors declare no conflict of interest. The funders had no role in the design of the study; in the collection, analyses, or interpretation of data; in the writing of the manuscript, or in the decision to publish the results.

\section{References}

1. Report on the 1st exploration of Admiral Yi's naval battle relics. Admiral Yi's Naval Battle Relics Exploration Unit. In Cultural Heritage Administration; Ministry of Culture and Public Communication: Sejong, Korea, 1974.

2. Report on the Underwater Excavation of Myeongnyang Site Near Jindo Island; National Research Institute of Maritime Cultural Heritage: Yonghae-dong, Korea, 2015.

3. Report II on the Underwater Excavation of Myeongnyang Site Near Jindo Island; National Research Institute of Maritime Cultural Heritage: Yonghae-dong, Korea, 2018.

4. Report on the Underwater Excavation near Nakwoldo Island, Yeonggwang; National Research Institute of Maritime Cultural Heritage: Yonghae-dong, Korea, 2019.

5. Report on the Underwater Excavation Near Taean Dangampo; National Research Institute of Maritime Cultural Heritage: Yonghaedong, Korea, 2019.

6. Ferentinos, G.; Fakiris, E.; Christodoulou, D.; Gerage, M.; Dimas, X.; Georgiou, N.; Kordella, S.; Papatheodorou, G.; Prevenios, M.; Sotiropoulos, M. Optimal sidescan sonar and subbottom profiler surveying of ancient wrecks: The 'Fiskardo' wreck, Kefallinia Island, Ionian Sea. J. Archaeol. Sci. 2020, 113, 105032. [CrossRef]

7. Kim, S.B. A Study on the MATLAB-based Chirp SBP Data Processing and Field Application. Ph.D. Thesis, Dong-A University, Busan, Korea, 2015.

8. Tamura, L.N.; Almeida, R.P.; Galeazzi, C.P.; Freitas, B.T.; Ianniruberto, M.; Prado, A.H. Upper-bar deposits in large Amazonrivers: Occurrence, morphology and internal structure. Sediment. Geol. 2019, 387, 1-17. [CrossRef]

9. Kim, S.B.; Ko, E.J.; Jung, Y.H.; Lee, Y.H.; Kim, J.H. Physical property analysis of sediments for development of maritime archaeological survey techniques. J. Korean Soc. Mar. Eng. 2014, 38, 333-341. [CrossRef]

10. Plets, R.; Quinn, R.; Forsythe, W.; Westley, K.; Bell, T.; Benetti, S.; McGrath, F.; Robinson, R. Using multibeam echo-sounder data to identify shipwreck sites: Archaeological assessment of the Joint Irish Bathymetric Survey data. Int. J. Naut. Archaeol. 2011, 40, 87-98. [CrossRef]

11. Quinn, R. Marine geophysical investigation of Northern Ireland of the inshore coastal waters. Int. J. Naut. Archaeol. 2000, 29, 249-298. [CrossRef]

12. Quinn, R.; Breen, C.; Forsythe, W. Integrated geophysical surveys of the French Frigate La Surveillante (1797), Bantry Bay, Co. Cork, Ireland. J. Archaeol. Sci. 2002, 29, 413-422. [CrossRef]

13. Quinn, R.; Forsythe, W.; Breen, C.; Dean, M.; Lawrence, M.; Liscoe, S. Comparison of the maritime sites and monuments record with side-scan sonar and diver surveys: A case study from Rathlin Island, Ireland. Geoarchaeology 2002, 17, 441-451. [CrossRef]

14. Simyrdanis, K.; Papadopoulos, N.; Cantoro, G. Shallow off-shore archaeological prospection with 3-D electrical resistivity tomography: The case of Olous (modern Elounda), Greece. Remote Sens. 2016, 8, 897. [CrossRef]

15. Weiss, E.; Ginzburg, B.; Cohen, T.R.; Zafrir, H.; Alimi, R.; Salomonski, N.; Sharvit, J. High resolution marine magnetic survey of shallow water littoral area. Sensors 2007, 7, 1697. [CrossRef] [PubMed]

16. Dhoop, T.; Stark, S.; Olaberria, J.P.; Whitewright, J. Quantifying ship shape in archaeology: Evaluating 3D geometric morphometrics. Int. J. Naut. Archaeol. 2020, 49, 49-64. [CrossRef]

17. Ono, R.; Katagiri, C.; Kan, H.; Nagao, M.; Nakanishi, Y.; Yamamoto, Y.; Takemura, F.; Sakagami, N. Discovery of iron grapnel anchors in early modern Ryukyu and management of underwater cultural heritage in Okinawa, Japan. Int. J. Naut. Archaeol. 2016, 45, 77-93. [CrossRef]

18. Hu, Y.; Xu, J.; Zhong, G.; Lin, A.; Fang, X.; Wang, L. The target comparison from different sidescan sonar system. In International Society of Offshore and Polar Engineers. In Proceedings of the 26th International Ocean and Polar Engineering Conference, Rhodes, Greece, 26 June-2 July 2016. ISOPE-I-16-553.

19. McCarthy, J.; Benjamin, J.; Winton, T.; van Duivenvoorde, W. The rise of 3D in maritime archaeology. In 3D Recording and Interpretation for Maritime Archaeology; McCarthy, J., Benjamin, J., Winton, T., van Duivenvoorde, W., Eds.; Springer Nature: Cham, Switzerland, 2019; pp. 1-11.

20. Kim, Y.J.; Cheong, S.; Lee, C.; Riedel, M.; Kim, C.S.; Koo, N.H.; Kim, B.Y. Application of pseudo-3D Chirp sub-bottom profiler survey: A case study of ancient wooden shipwreck site, west coast of Korea. Explor. Geophys. 2021, 52, 109-121. [CrossRef]

21. Sakellariou, D.; Georgiou, P.; Mallios, A.; Kapsimalis, V. Searching for ancient shipwrecks in the Aegean Sea: The discovery of Chios and Kythnos Hellenistic wrecks with the use of marine geological-geophysical methods. Int. J. Naut. Archaeol. 2007, 36, 365-381. [CrossRef] 
22. Carreón-Freyre, D.; Cerca, M.; Hernández-Marin, M. Correlation of near-surface stratigraphy and physical properties of clayey sediments from Chalco basin, Mexico, using Ground Penetrating Radar. J. Appl. Geophy. 2003, 53, 121-136. [CrossRef]

23. Shin, C.J.; Jang, I.S.; Kim, K.H.; Lee, S.H. Performance analysis of sonar system applicable to underwater construction sites with high turbidity. J. Korea Acad. Industr. Coop. Soc. 2013, 14, 4507-4513. [CrossRef] 